\title{
MENDIDIK ANAK MENJADI SUPUTRA MENURUT TEKS CANAKYA NITISASTRA
}

\author{
Oleh \\ Putu Sanjaya \\ Dosen STAHN Mpu Kuturan \\ sanjaya_putu95@yahoo.com
}

\begin{abstract}
Hindu Religious Education is basically the implementation and internalization of the teachings and values derived from the Vedic scriptures and other Hindu religious literature. One of the Hindu religious literature that teaches his people about the procedures for moral behavior includes teaching how to form descendants or future generations (read: children) which is the text of Canakya Nitisastra. The text of Canakya Nitisastra is a text which is a concise form of what is contained in the book Arthasastra.

This paper presents passages from verses from the text of Canakya Nitisastra which specifically teaches how to create a good education for children so that later they will become supernatural children. Through the textual approach, in Canakya Nitisastra it was found about the importance of children's education through socializing and planting the teachings of decency and sanctity of parents.
\end{abstract}

Key words : Educating Children into Suputra According to Canakya Nitisastra Text

\begin{abstract}
ABSTRAK
Pendidikan Agama Hindu pada dasarnya merupakan implementasi dan internalisasi dari ajaran-ajaran dan nilai-nilai yang bersumber dari kitab suci Weda serta susastra-susastra agama Hindu lainnya. Salah satu susastra agama Hindu yang mengajarkan kepada umatnya mengenai tata cara berperilaku yang susila termasuk pula mengajarkan bagaimana membentuk keturunan atau generasi penerus (baca: anak) yang suputra adalah teks Canakya Nitisastra. Adapun teks Canakya Nitisastra merupakan sebuah teks merupakan bentuk ringkas dari apa yang terdapat dalam kitab Arthasastra.

Tulisan ini mengetengahkan petikan-petikan dari bait-bait sloka dari teks Canakya Nitisastra yang khusus mengajarkan bagaimana mewujudkan pendidikan yang baik pada anak sehingga nantinya menjadi anak yang suputra. Melalui pendekatan tekstual, dalam Canakya Nitisastra ditemukan tentang pentingnya pendidikan anak melalui cara bergaul dan penanaman ajaran kesusilaan dan kesucian dari orang tua.
\end{abstract}

Kata kunci : Mendidik Anak Menjadi Suputra Menurut Teks Canakya Nitisastra

\section{PENDAHULUAN}

Anak adalah generasi penerus keluarga dan juga bangsa serta negara. Kehadiran seorang anak merupakan dambaan bagi setiap keluarga. Artinya, setiap keluarga pasti menginginkan untuk memiliki anak dalam kehidupan rumah tangganya. Anak adalah individu yang sangat bernilai. Anak begitu lahir telah memperoleh doa dan harapan dari orang tuanya. Setiap orang tua pasti mendoakan supaya Tuhan senantiasa melimpahkan anugrah yang terbaik baginya serta berharap anak akan memperoleh rezeki serta kehidupan yang baik serta berguna bagi 
keluarga dan negerinya. Secara implisit doa dan harapan itu sudah pasti menginginkan anak yang dilahirkan menjadi anak yang baik, yang menghormati orang tuanya dan mencintai seluruh anggota keluarganya. Keadaan anak yang demikian dalam agama Hindu disebut dengan anak yang Suputra.

\section{PEMBAHASAN}

Kehadiran seorang anak dalam keluarga adalah sebuah dambaan, terlebih seorang anak yang suputra. Hal itu ditegaskan dalam Canakya Nitisastra sebagaimana petikan sloka berikut:

Ekanapi suvrksena puspitena sugandhita vasitam tadvanam sarvam suputrena kulam yatha (Bab III Sloka 14)

Terjemahannya:

Seluruh hutan menjadi wangi hanya karena ada sebuah pohon dengan bunga indah dan harum semerbak. Begitu juga halnya kalau di dalam keluarga terhadap seorang anak yang suputra.

Ekenapi suputrena vidya yuktena sadhuna ahladitam kulam sarvam yatha candrena sarvari (Bab III Sloka 16).

Terjemahannya:

Sebagaimana bulan menerangi malam hari dengan cahayanya yang terang menyejukkan, begitulah seorang anak suputra yang berpengetahuan rohani, insaf akan dirinya dan juga bijaksana. Anak suputra ini menyebabkan seluruh keluarganya selalu dalam kebahagiaan.

Kim jatair bahubhih putraih soka santapakarakaih varamekah kulalambi yatra visramyate kulam (Bab III Sloka 17)

Terjemahannya:

Apa gunanya melahirkan anak terlalu banyak kalau mereka hanya mengakibatkan kesengsaraan dan selalu memberikan kedukaan. Walaupun hanya seorang anak tetapi berkepribadian utama dan membantu keluarga, satu anak yang meringankan keluarga inilah yang paling baik.
Berdasarkan petikan sloka-sloka di atas, sangatlah utama keadaan seorang anak suputra. Ia mampu membawa kedamaian dan kebahagiaan bagi keluarganya. Akan tetapi untuk menjadikan anak menjadi suputra bukanlah persoalan yang mudah.

Mendidik anak untuk menjadi seorang suputra sangatlah penting. Memberikan pendidikan kepada anak bukan hanya sekadar menyekolahkan anak sampai ke jenjang yang paling tinggi. Tidak jarang justru yang terjadi malah jauh dari harapan. Banyak kasus terjadi dimana orang tua memberikan pendidikan kepada anak sampai kepada jenjang yang begitu tinggi akan tetapi anak justru memiliki tabiat yang menyimpang. Hal ini tentu bertentangan dengan apa yang menjadi tujuan dan idealisme pendidikan itu sendiri. Pendidikan pada dasarnya menginginkan anak didik untuk menjadi seorang yang memiliki nilai-nilai dan susila dalam setiap perilakunya sehingga dapat menjadi insan yang mulia. Oleh karena demikian maka pendidikan kepada anak guna menjadikannya seorang anak yang suputra sangatlah dibutuhkan usaha yang komprehensif dan berkesinambungan. Dan sesungguhnya itu merupakan dharma (kewajiban) bagi setiap orang tua terhadap anaknya.

Dalam kitab suci Sarasamuccaya, ada tiga perihal yang dilakukan oleh orang tua terhadap anaknya. Sebagaimana yang disebutkan dalam petikan sloka 242 berikut:

Tlu pratyekaning bapa, tingkahnya carirakrt, pranadata, annadata, carirakrt ngaraning sangkaning carira, pranadata ngaraning manya hurip, annadata ngaraning maweh amangan nagingwani wih.

Terjemahannya:

Tiga perincian bapa (orang tua) itu menurut perikeadaanya yaitu carirakrt, pranadata, annadata; carirakrt artinya yang mengadakan tubuh (fisik), pranadata artinya yang memberikan hidup, annadata artinya yang memberi makan serta mengasuhnya.

Berdasarkan petikan sloka di atas, maka secara alamiah orang tua memiliki kodrat menciptakan anak melalui perkawinan yang selanjutnya dilahirkan, serta 
memelihara anak dengan sebaik-baiknya. Memelihara, merawat serta mendidik anak merupakan tanggung jawab bagi setiap orang tua. Berkaitan dengan pendidikan, orang tua sudah sepatutnya mendidik anak agar menjadi anak yang suputra. Dalam Canakya Nitisastra disebutkan:

Putras ca vividhaih silair niyojyah satatam budhaih niti jnah sila sampanna bhavanti kula pujitah (Bab II Sloka 10).

Terjemahannya:

Orang bijaksana hendaknya mengajarkan putranya tata susila, pengetahuan Nitisastra dan ilmu pengetahuan suci lainnya, sebab seorang putra yang mahir dalam pengetahuan Nitisastra dan pengetahuan suci lainnya akan menyebabkan keluarganya terpuji.

Mata satru pita bairi yena balo na pathitah na sobhate sabha madhye hamsa madhye bako yatha (Bab II Sloka 11).

Terjemahannya:

Seorang bapak dan ibu yang tidak memberikan pelajaran (kesucian) kepada anaknya, mereka berdua adalah musuh dari anak tersebut. Anak tidak akan ada artinya di masyarakat, bagaikan seekor bangau di tengah-tengah kumpulan burung angsa.

Oleh karena pentingnya anak suputra, maka sangatlah penting bagi setiap orang tua untuk memberikan pendidikan kepada anak terutama mengenai pengetahuanpengetahuan suci serta ajaran-ajaran yang terdapat dalam Nitisastra. Selanjutnya mengenai cara mendidik anak, teks Canakya Nitisastra menyebutkan:

Lalanad bahavo dosas tadanad bahavo gunah tasmat putram ca sisyamca tadayen na tu lalayet (Bab II Sloka 12)

Terjemahannya:

Anak yang didik dengan memanjakan akan menjadi durhaka dan jahat. Sedangkan dengan memberikan hukuman-hukuman ia akan menjadi baik. Oleh karena itu didiklah putra-putri dan murid-murid anda dengan cara memberikan hukuman-hukuman dan tidak dengan cara memanjakannya.

Sloka di atas memiliki keterkaitan dengan sloka 18 pada Bab III yang menyebutkan:

Lalayet panca varsani dasa varsani tadayet prapte tu sodase varse putram mitravadacaret

Terjemahannya:

Asuhlah putra dengan cara memanjakannya sampai berumur lima tahun, memberikan hukuman-hukuman selama sepuluh tahun berikutnya. Kalau ia sudah menginjak umur enam belas tahun didiklah ia dengan cara berteman.

Petikan sloka di atas mengajarkan bagaimana menggunakan hukuman untuk mendidik anak dan murid. Dalam hal ini bukanlah menghukum anak dengan semaumaunya. Sedikit kesalahan sudah dihukum dengan berat, sama sekali tidak memberikan dampak baik yang bermanfaat bagi anak itu sendiri. Hukuman hendaknya diberikan secara bertahap melalui nasehat-nasehat, larangan, teguran, peringatan, peringatan tegas, sampai pada hukuman yang memberinya efek jera. Akan tetapi bila anak sudah tidak melakukan kesalahan atau mau memperbaiki kesalahannya maka hukuman yang diberikan dapat dihentikan dan digantikan dengan sikap baik dan ramah kembali dari orang tua.

Canakya Nitisastra Bab II Sloka 13 juga menyebutkan: Slokena va tadardhena tadarddharddhaksarena va avandhyam divasam kuryad danadhyayana karmabhih.

Terjemahannya:

Isilah waktu setiap hari dengan menghafalkan satu sloka, satu ayat, atau setengah sloka, atau seperempat sloka, atau pun satu huruf dari sloka tersebut. Atau isilah hari-hari anda dengan bersedekah, belajar kitab-kitab suci dan kegiatan bermanfaat lainnya. Dengan demikian hari-hari anda akan menjadi berarti. 
Sloka diatas mengajarkan agar setiap orang senantiasa mengusahakan untuk mengisi hari-harinya dengan kegiatan yang positif atau baik. Untuk menghindarkan diri dari pikiran, perkataan, serta perbuatan yang menyimpang, maka sangatlah penting memposisikan diri untuk selalu berada dalam kegiatan-kegiatan yang baik dan bermanfaat bagi diri sendiri maupun orang lain. Aktivitas seperti demikian hendaknya dilakukan dan dicontohkan oleh setiap orang tua kepada anaknya. Dalam hal ini orang tua harus dapat menjadi contoh terhadap kebiasaan-kebiasaan yang baik untuk ditiru dan diteladani oleh anak-anaknya.

Canakya Nitisastra Bab II sloka 19 menyebutkan:

Duracari duradrstih duravasi ca durjanah yan maitri kriyate pumsa sa tu sighram vinasyati

\section{Terjemahannya:}

Kalau seseorang berteman dengan orang yang tingkah lakunya tidak baik, dengan orang yang pengelihatannya jahat, dengan orang yang tinggal di tempat-tempat kotor dan tidak suci, bergaul dengan penjahat, segera menemui kebinasaan.

Petikan sloka di atas memiliki kesamaan maksud dengan yang terdapat dalam kitab suci Sarasamuccaya sloka 305 yang menyebutkan sebagai berikut:

Kunang ulaha, yan pasahaya kita, sang sadhu juga sahayanta, yan ta gawaya pakadangan, sang sadhu juga kadanganta, yadyapin patukara tuwi, nguniweh yan samitra lawan sang sadhu juga, apan pisaningun hana kayogyaning tan sadhu.

Terjemahannya:

Jika anda berkawan, maka hendaklah orang yang berbudi luhur saja menjadi kawan anda; jika hendak mencari persaudaraan orang yang berbudi luhur itu anda usahakan untuk dijadikan persaudaraan; andaikata sampai berbantah sekalipun, apalagi jika bersahabat hendaklah dengan orang yang baik budi itu; sebab mustahil tidak akan kelimpahan budi luhur itu jika telah bergaul dengan sang sadhu.

Sloka di atas mengajarkan bahwa teramat penting untuk menjaga pergaulan. Dalam hal ini bukan bermaksud untuk memilih teman, akan tetapi untuk memperoleh kehidupan yang baik maka diusahakan sekali dalam menjalin hubungan pergaulan hendaknya hanyalah kepada orangorang yang baik pula. Demikian pula halnya, guna membentuk anak yang suputra maka pergaulan anak juga hendaknya mendapat perhatian dari orang tua.

Berdasarkan petikan-petikan sloka di atas, maka sesungguhnya ajaran agama Hindu (yang tertuang dalam teks Canakya Nitisastra) mengajarkan kepada orang tua bahwasanya agar anak dalam keluarga menjadi anak yang suputra, maka yang pernting untuk diperhatikan adalah, bagaimana menanamkan kebiasaankebiasaan baik kepada diri anak dan juga di dalam keluarga, menerapkan reward and punishment dalam setiap perbuatan baik dan juga kesalahan yang dilakukan oleh anak, serta memperhatikan dengan siapa saja anak menjalin hubungan pertemanan dalam pergaulannya.

\section{SIMPULAN}

Berdasarkan uraian pada Bab Pembahasan di atas, dapat sekiranya disimpulkan bahwa teks Canakya Nitisastra mengajarkan pembentukan anak suputra melalui empat hal yakni, perlakuan atau sikap orang tua kepada anak berdasarkan usia, menerapkan reward and punishment, menjalankan kebiasaan-kebiasaan baik dalam keluarga, serta membentuk pergaulan positif dalam kehidupan bermasyarakat. 


\section{DAFTAR PUSTAKA}

Dharmayasa, I Made. 1995. Canakya Nitisastra. Denpasar: Yayasan Dharma Narada

Kadjeng, I Nyoman. 1999. Sarasamuccaya. Surabaya: Paramita

Maswinara, I Wayan. 2000. Hita Upadesa. Surabaya: Paramita

Mishra, P.S. 2008. Hindu Dharma Jalan Kehidupan Universal. Surabaya: Paramita

Pudja, G. 2004. Bhagawad Gita. Surabaya: Paramita

Pudja, G. \& Sudharta, Tjok. Rai. 2002. Manawa Dharmasastra. Jakarta: Pelita Nursatama Lestari

Sanjaya, Putu. 2013. Menggali Nilai Etika dalam Purana. Surabaya. Paramita

Somvir. 2001. 108 Mutiara Veda. Surabaya: Paramita

Sudharta, Tjok. 2004. Slokantara Untaian Ajaran Etika. Surabaya: Paramita

Titib, I Made. 1996. Veda Sabda Suci Pedoman Praktis Kehidupan.

Surabaya: Paramita 